\title{
Assessment of Autobiographical Memory Narratives in Psychotherapy with Borderline Personality Disorder: An exploratory study
}

\author{
Deepti Guruprasad ${ }^{1} \&$ Poornima Bhola ${ }^{1 凶}$
}

\begin{abstract}
Autobiographical memory narratives that emerge in therapeutic discourse can aid the understanding of the client's narrative identity and the identification of central themes or conflicts. The study aimed to examine the structure and thematic content of autobiographical memory narratives of five clients with Borderline Personality Disorder (BPD), during the early phase of individual psychotherapy. The Biopsychosocial Interview gathered narrative material about the clients' life experiences in childhood and adulthood and explored the history of psychological difficulties and/or disorders. The interview and the first five sessions of psychotherapy for each client were audio recorded, transcribed and coded for analysis. The Coding System for Autobiographical Memory Narratives in Psychotherapy was used to identify autobiographical memory narratives from the clients' life experiences, rate the narrative complexity, specificity and integration, and derive narrative patterns or themes. Analysis indicated that the narratives had a moderate level of complexity, low levels of specificity, were predominantly autobiographical, poorly integrated and revealed dominant themes of contamination. Narrative themes of agency, communion and redemption were relatively lower among the clients. The implications for therapeutic practice, training of clinicians and future research are discussed.
\end{abstract}

Keywords: autobiographical memory, narratives, borderline personality disorder, psychotherapy

Human beings create meaning and use language to shape their personal experiences into stories, or narratives (Angus \& Greenberg, 2011). From the narrative standpoint, psychological difficulties indicate situations where important aspects of one's lived experience are not adequately represented in the self narrative revealed during therapy. By helping the client reconstruct problematic self narratives to become more coherent, complex and inclusive, therapy is considered a process of 'story repair'

\footnotetext{
${ }^{1}$ Department of Clinical Psychology, National Institute of Mental Health and Neuro Sciences, Bangalore, 560029 India.

$\triangle$ Correspondence concerning this paper should be addressed to Poornima Bhola, Department of Clinical Psychology, National Institute of Mental Health and Neuro Sciences, Bangalore, 560029 India. E-mail: poornimabhola@gmail.com.
}

(Avdi \& Georgaca, 2007)

There is a growing interest in the concept of 'narrative identity' and related processes or dimensions (McAdams \& Pals, 2006; McLean, 2008) as tools to understand psychotherapy processes and change (Angus, Levitt \& Hardtke, 1999; Angus et al., 2012; Boritz, Angus, Monette, Hollis-Walker, \& Warwar, 2011; Luborsky, 1977; Matos, Santos, Goncalves, \& Martins, 2009; Mendes et al., 2010; Singer, Blagov, Berry, \& Oost, 2013; Singer \& Bonalume, 2010a). Narrative identity is referred to as "the internal, dynamic life story that an individual constructs to make sense of his or her life" (Bauer, McAdams, \& Pals, 2008). Narratives that may emerge in therapy may range from descriptions of a specific event, to an overarching life story that spans across several years.

The ability to construct a coherent narrative is ba- 
sed on memory, particularly autobiographical memory. Autobiographical memories are "transitory dynamic mental constructions generated from an underlying knowledge base" (Conway \& PleydellPearce, 2000, p. 261). Subsequently, the qualitative aspects of autobiographical memory, including emotionality (or affective content and tone of the narrative), specificity, level of complexity, and coherence may significantly impact identity-construction (Jorgensen et al., 2012). A healthy autobiographical memory system, translating into a healthy narrative identity, is understood to have three features-memory specificity, a greater emphasis on positive affective content, and the capacity for integration (Singer et al., 2013). It has been suggested that an ongoing sense of unity and direction that links an individual's past, present, and future selves is provided by a coherent and flexible narrative identity that is linked to an adaptive and flourishing autobiographical memory system (Singer et al., 2013).

Singer and Bonalume (2010a) developed a comprehensive coding system to reliably identify autobiographical memory narratives in the flow of clinical interaction and analyze the qualitative aspects of narratives. These included their complexity (causality, temporality, and outcome, representations of protagonists and antagonists, along with emotional responses), specificity (recall of a unique set of events confined to a single episode within a 24-hour period), integration and meaning-making, and relevant themes. In a single case study, the authors applied the coding system to the diagnostic interviews with a client, to generate predictions about the course of psychotherapy, possible resistances and therapist-client relationship. Results were then compared to the report of the client's actual therapeutic outcome.

The exploration of psychotherapy narratives, although a potentially valuable method of obtaining rich data about complex client difficulties and emergent therapy processes, is a relatively understudied approach. While studies have attempted to understand client narratives and change processes in therapy, the client groups involved have predominantly been individuals with depression. Some of these studies with depressed clients examined the transformation of 'burden metaphors' to that of 'unloading the burden' over the course of shortterm process-experiential therapy in good outcome dyads (Levitt, Korman, \& Angus, 2000); the relationship between changes in level of depression, emotional arousal expressed and autobiographical memory specificity across psychotherapy sessions (Boritz, Angus, Monette, \& Hollis-Walker, 2008; Boritz, et al., 2011); and the examination of in-session narrative processes to track common innovative moments of change across emotion focused therapy (Mendes et al., 2010).

Theoretical viewpoints have postulated that the narratives of individuals with borderline personality disorder (BPD) may contain large gaps or inconsistencies with associated difficulties in maintaining a stable sense of themselves or others. Fuchs (2007) conceptualised BPD as a disorder of intersubjectivity with a fragmented self-narrative manifested in the typical clinical features of affect dysregulation, impulsivity, splitting of object relations, unstable relationships and chronic emptiness. According to Fonagy (2000), early experiences of lack of empathy or maltreatment by attachment figures impair the child's reflective capacities and sense of self when attachment representations are being formed. These deficits in mentalizing, the capacity to step inside another person's shoes, lead to impairments in the ability to link the past, present and future towards the formation of autobiographical memories and coherent narrative identities.

Although conceptually, fragmented self-narratives are considered a key feature of borderline symptomatology, there is limited empirical research in this area. A major focus has been on autobiographical memory specificity among BPD clients. Some studies found that BPD clients had over-general retrieval of autobiographical memories (Jones et al., 1999; Startup et al., 2001) However findings about the relationship between reduced memory specificity and BPD features have been inconsistent (Arntz, Meeren, \& Wessel, 2002; Kremers, Spinhoven, \& Van der Does, 2004; Maurex et al., 2010; Reid \& Startup, 2010; Renneberg, Theobald, Nobs, \& Weisbrod, 2005).

One study revealed that borderline clients had more concrete, 'literal' narrative modes characterized by immediate emotional expression and distancing from the content during therapy compared to the 'representational' narrative modes or reflection in the non-borderline counterparts (Ramussen \& Angus, 1996). Adler, Chin, Kolisetty and Oltmanns (2012) analysed life story interviews among mid-life adults with and without features of BPD. Those with features of BPD had significant disruptions in narrative coherence and in emergent themes describing agency and fulfilment of communion needs. The Core Conflictual Relationship method (Luborsky, 1977) identified the most common relational patterns among inpatients with borderline personality disorder as; the wish to be loved and understood, experiencing others as rejecting and responding with depression and disappointment (Chance, Bakeman, Kaslow, Farber, \& BurgeCallaway, 2000). Overall, studies have primarily focused on the coherence or organisation of narratives relative to aspects of narrative typology, content and quality.

Research points to markedly negative affective experiences such as abuse, neglect, environmental instability and parental psychopathology as developmental antecedents of individuals with BPD (Helgeland \& Torgersen, 2004). This suggests the rele- 
vance of personal memories and referencing of past events during the process of therapy with clients diagnosed with BPD. The eliciting of autobiographical memory narratives early in therapy may positively impact the unfolding of psychotherapy by evoking a feeling of being "listened to" and having their story understood for clients. For therapists, this can lead to an enhanced understanding of the client's core vulnerabilities and their life story narrative and the planning of responsive therapeutic interventions.

\section{The present study}

While theoretical models of borderline psychopathology suggest that narratives would tend to be fragmented, less coherent, and less integrated with predominantly negative themes, there has been little research to confirm these hypotheses. The few studies have focused largely on selected aspects of narratives like specificity or coherence. The objective of the present study was to identify and categorize the structure and content of autobiographical memory narratives that emerged in the initial biospsychosocial interviews and the early psychotherapy sessions of 5 clients with BPD using The Coding System for Autobiographical Memory Narratives in Psychotherapy (Singer \& Bonalume, 2010a). As this was an exploratory pilot study, the first five sessions of psychotherapy were selected to capture personally relevant autobiographical memories in the initial phase of the therapeutic interaction. In addition, since research indicates changes in memory specificity, content and themes as therapy progresses (Adler, 2012; Boritz, Angus, Monette, \& Hollis-Walker, 2008), the present study looked at the qualities of narratives that clients came into therapy with. The assessment of both the structure and content of autobiographical memory narratives that emerge in psychotherapy with individuals with borderline personality disorder would contribute to the emerging literature in the area of personality research and psychotherapy processes.

\section{Method}

\section{Participants}

Purposive sampling identified a sample of five cli- ents diagnosed with Borderline Personality Disorder, referred for individual psychotherapy, from the Adult Psychiatry units of a tertiary care psychiatric hospital, in India. Both inpatients and outpatients with a diagnosis of Emotionally Unstable Personality Disorder, borderline type (ICD-10, World Health Organization, 1992) or Borderline Personality Disorder (DSM-IV- TR, American Psychiatric Association, 2000), within the age of range of 18 to 45 years, conversant in English, Hindi or Kannada languages with a minimum $7^{\text {th }}$ grade education were included in the study. Those with a diagnosis of organic mental disorders, mental retardation, substance use disorders, schizophrenia, schizotypal, delusional disorders or current episode of affective disorder were excluded.

After screening 17 patients, 8 who provided informed consent were recruited and 5 of them completed the study requirements. The socio-demographic details of the sample are provided in Table 1. The principles and criteria of clinical representativeness (Shadish, Matt, Navarro, \& Phillips, 2000) were followed for sample selection and treatment implementation.

\section{Measures}

Socio-Demographic data . This was used to collect information including age, sex, education, occupation, marital status, family type, presenting problems and any prior experience of therapy (see Table 1).

The biopsychosocial interview (Singer \& Bonalume, 2010a). It was developed in The Association for Research in Clinical Psychology (A.R.P., Milan) as a part of the comprehensive assessment process of clients who are provided psychological intervention combining relational and cognitive-behavioural components. This measure comprises $5 \mathrm{sec}-$ tions including: (1) family history; (2) client's life history; (3) client's academic history and job career; (4) sexuality and romantic relationships; and (5) history of psychological difficulties and/or disorders. Each section has about ten sub-sections containing statements that are open-ended, provide pointers for the interviewer to document specific factual information (such as age, living arrange-

Table 1. Socio-demographic characteristics of the sample $(N=5)$

\begin{tabular}{|c|c|c|c|c|c|}
\hline Clients & A & B & C & D & E \\
\hline Age & 23 & 28 & 23 & 22 & 44 \\
\hline Sex & Female & Female & Female & Female & Male \\
\hline Educational level & Undergraduate & High school & Under-graduate & Under-graduate & Under-graduate \\
\hline Employment & Employed & Unemployed & Unemployed & Unemployed & Unemployed \\
\hline Marital Status & Single & Married & Single & Single & Divorced \\
\hline
\end{tabular}


ment, relationship qualities), and also allow for additional recording of information. The client is encouraged to recall and reflect on experiences, while the interviewer attends to associated emotional responses and uses follow-up questions that may offer opportunities to make connections across important experiences. This measure has been used in a single-case design (Singer \& Bonalume, 2010a) and in unpublished research work with 30 clients (Bonalume, personal communication). The coding of emergent narratives was used to guide case conceptualization and the identification of metaphors and themes to assist the therapist in tracking the relationship dynamics within treatment. The biopsychosocial interview process is described as holistic and person based, aimed at evoking a client's strengths, resources and resiliencies (Singer \& Bonalume, 2010b). In the present study, the interview was used to elicit relevant autobiographical memory narratives from the client's life experiences, after the intake session and before initiation of therapy. The process extended to a maximum of three sessions per client.

\section{Treatment Approach}

The theoretical framework of psychotherapy and techniques adopted were eclectic and drawn from Dialectical Behavior Therapy (Linehan, 1993a; 1993b), Emotion Focused Therapy (Greenberg, Rice, \& Elliott, 1993) and Supportive Psychotherapy (Pinsker, 1997). Treatment was open ended in length determined by the client's needs and/or the duration of the client's inpatient hospitalisation. The psychotherapy sessions ranged from a total of 11 to 25 sessions.

\section{Therapist}

The therapist was a 25 year old, female Masters graduate in Clinical Psychology, in the second year of clinical training in psychotherapy in a two year postgraduate M. Phil programme. All therapy cases were supervised, with a range of 10 to 15 supervision discussions per client.

\section{Procedure}

The study procedure is described in Figure 1. Written informed consent was obtained from all participants in the study. The socio demographic sheet was administered in the intake session. The biopsychosocial interview was conducted for 2 to 3 sessions per client, after which individual psychotherapy sessions were initiated. The interview and the first five sessions of individual psychotherapy for each client were audio recorded and transcribed into verbal text.

A total of 36 session transcripts (11 biopsychosocial interview sessions and 25 therapy sessions) were coded as per the manual of The Coding System for Autobiographical Memory Narratives in Psychotherapy-CS-AMNP (Singer \& Blagov, 2002) to identify autobiographical memory narratives across psychotherapy sessions.

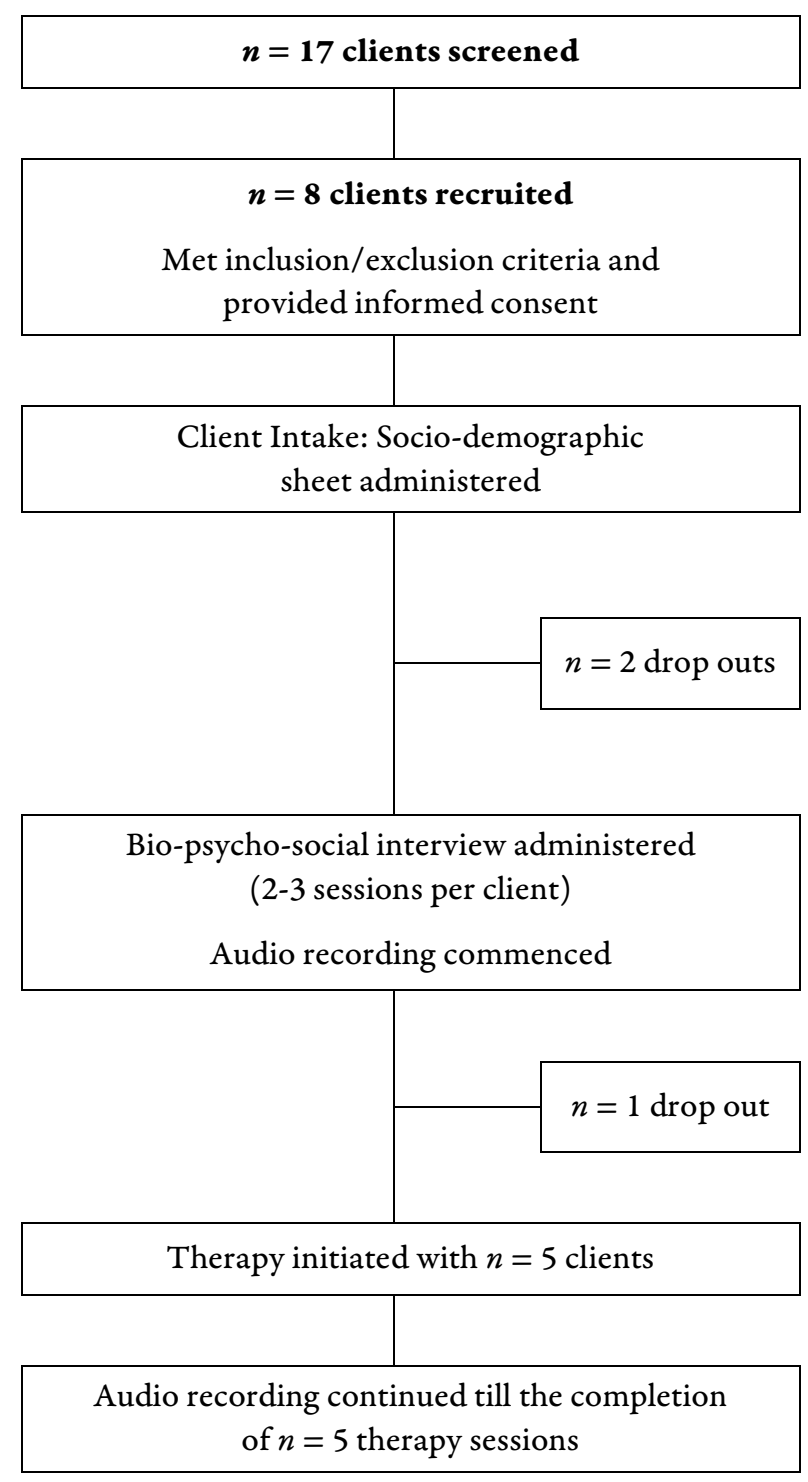

Figure 1. Flow chart of Study Procedure.

The following steps were used during the coding process:

(a) Topic definition. It involved division of the transcripts into discrete topic segments in order to isolate distinct narrative units.

(b) Narrative complexity coding. The complexity of narratives was assessed based on the causality, temporality, and outcome of narratives, along with the representations of protagonists and antagonists and their emotional responses. Narrative Complexity was coded for each segment, using a 5-point scale with 5 points indicating highest complexity and 1 point indicating the lowest.

(c) Defining autobiographical memory narratives. For the narratives that were found to have a rating of 3 
or greater in complexity, the next step involved identifying narrative units which concerned events that happened at least one year ago, and which were witnessed or experienced by the client first-hand. The specified time frame ensures that the memory narrative has had time to connect to the enduring meaning and affective networks of the long-term self.

(d) Specificity coding. Narratives were classified into one of the 3 types, based on specificity- "single event memories are those that are traceable to a specific defined moment in time within one 24-hour period, summary episodic memories that collect together a number of closely-occurring single events into one compacted time period, and summary generic memories that blend the repeated occurrences of a similar event separated over larger blocks of time into an amalgamated single recollection."

(e) Integration coding. Identifying the degree of integration of a particular memory with the larger selfconcept of the individual. Integrative memories involve stepping back from the memory and extracting a lesson or making meaning out of the same, which has implications for the understanding of the self.

(f) Thematic analysis. Narratives were coded into 4 themes; (1) Agency, themes of power, achievement, mastery, independence, autonomy, separation; (2) Communion, themes of relationship, connection, intimacy, nurturance, helping, togetherness; (3) Redemption, negative events that begin with themes of struggles, obstacles, and setbacks, but end with moments of triumph, growth, rejuvenation, and positive emotion; (4) Contamination, sequences begin with hope or positive circumstances and end in frustration, disappointment, and dejection.

The reliability and validity for coding specificity and integration have been established (Singer \& Blagov, 2002) and this coding system has been ex- tensively used in research with a range of psychological disorders (Singer, Blagov, Berry, \& Oost, 2013). The highest inter-rater reliability was found when scoring for two levels of structure (specific events vs. episodic \& generic, Cohen's kappa $=.80-$ $.98)$ and two levels of meaning (integrative $v s$ nonintegrative, $\kappa=.70)$. Blagov and Singer (2004) confirmed adequate inter-rater reliability in a study of 1040 self-defining memories obtained from undergraduate psychology students. The overall Cohen's kappa was found to be .828 for two levels of structure and .718 for meaning. There was a positive correlation between number of summary memories and levels of defensiveness measured by the Weinberger Adjustment Inventory- Short Form (Blagov \& Singer, 2004)

\section{Results}

Inter-rater reliability was calculated for a sample of three session transcripts coded by the researcher and an independent rater, a clinical psychologist with over 15 years of therapy and research experience (Cohen's kappa -0.88 to 1.00 ). Frequencies and percentages were calculated for the coding categories of the CS-AMNP.

Applying the CS-AMNP, it was found that the total number of topic segments across the interview and therapy sessions ranged from 56 to 119 for the 5 clients. Figure 2 indicates the narrative complexity coding for the topic segments (combining the data from biopsychosocial interviews and the first five therapy sessions) of all 5 clients, rated on a 5 point scale. The predominant level of complexity of narratives was found to be at 3 points. Stories predominantly had some causal linkages among the events, but without clear temporal sequencing and a confused or absent outcome of the events.

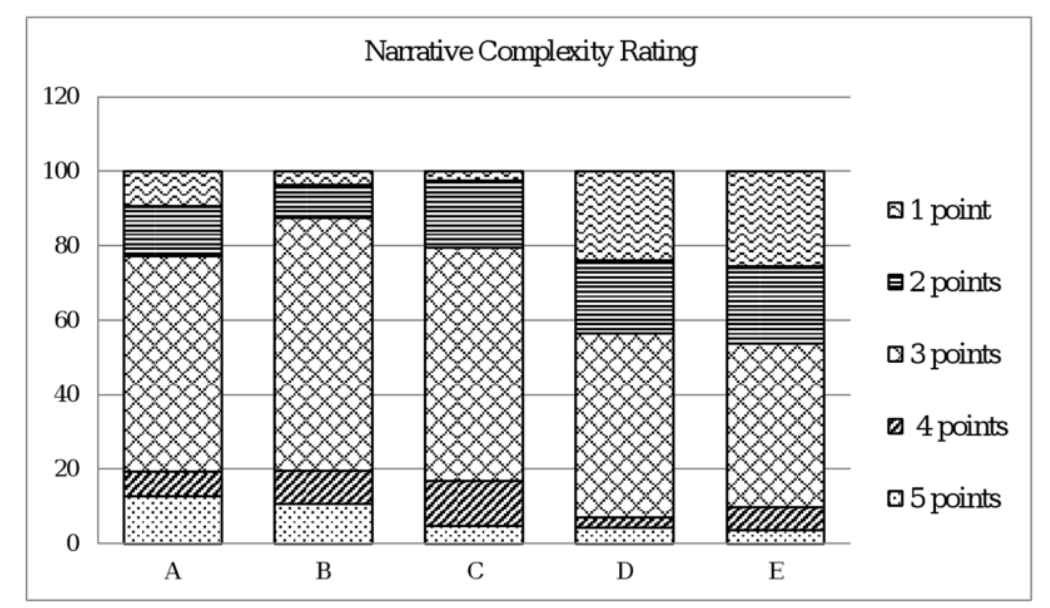

Figure 2. Percentage distribution of topic segments rated for narrative complexity from both biopsychosocial interview sessions and first five therapy sessions combined $(n=5)$. Narrative Complexity was coded for each topic segment, using a 5-point scale with 5 indicating highest complexity and 1 indicating the lowest. 
Table 2. Percentage distribution of topic segments rated for narrative complexity in the biopsychosocial interview sessions and first five therapy sessions $(n=5)$

\begin{tabular}{|c|c|c|c|c|c|c|c|c|c|c|}
\hline \multirow[b]{2}{*}{ Client } & \multicolumn{2}{|c|}{$\begin{array}{c}5 \text { points } \\
\%\end{array}$} & \multicolumn{2}{|c|}{$\begin{array}{c}4 \text { points } \\
\%\end{array}$} & \multicolumn{2}{|c|}{$\begin{array}{c}3 \text { points } \\
\%\end{array}$} & \multicolumn{2}{|c|}{$\begin{array}{c}2 \text { points } \\
\%\end{array}$} & \multicolumn{2}{|c|}{$\begin{array}{c}1 \text { point } \\
\%\end{array}$} \\
\hline & $\mathrm{BPS}^{\mathrm{a}}$ & Therapy & $\mathrm{BPS}^{\mathrm{a}}$ & Therapy & $\mathrm{BPS}^{\mathrm{a}}$ & Therapy & $\mathrm{BPS}^{\mathrm{a}}$ & Therapy & $\mathrm{BPS}^{\mathrm{a}}$ & Therapy \\
\hline A & 14.81 & 7.89 & 8.64 & 2.63 & 49.38 & 76.32 & 16.05 & 7.89 & 11.11 & 5.26 \\
\hline B & 7.89 & 10.52 & 10.53 & 10.52 & 71.05 & 57.89 & 10.53 & 15.79 & 0.00 & 5.26 \\
\hline $\mathrm{C}$ & 3.23 & 9.52 & 12.90 & 9.52 & 66.13 & 52.38 & 16.13 & 23.81 & 1.61 & 4.76 \\
\hline $\mathrm{D}$ & 2.63 & 6.06 & 2.63 & 3.03 & 68.42 & 27.27 & 18.42 & 21.21 & 7.89 & 42.42 \\
\hline $\mathrm{E}$ & 1.58 & 10.52 & 4.76 & 10.52 & 39.68 & 57.89 & 22.22 & 15.79 & 31.74 & 5.26 \\
\hline
\end{tabular}

Note. Narrative Complexity was coded for each topic segment, using a 5-point scale with 5 indicating highest complexity and 1 indicating the lowest.

${ }^{a}$ Biopsychosocial interview

Table 3. Percentage distribution of topic segments coded for specificity in the biopsychosocial interview sessions and first five therapy sessions $(n=5)$

\begin{tabular}{|cccccccccc|}
\hline & \multicolumn{3}{c}{$\begin{array}{c}\text { Summary Generic } \\
\text { \% }\end{array}$} & \multicolumn{3}{c}{$\begin{array}{c}\text { Summary Episodic } \\
\%\end{array}$} & \multicolumn{3}{c|}{$\begin{array}{c}\text { Single-event } \\
\%\end{array}$} \\
\cline { 2 - 10 } Client & BPS $^{\text {a }}$ & Therapy & Combined & BPS $^{\text {a }}$ & Therapy & Combined & BPS $^{\text {a }}$ & Therapy & Combined \\
\hline A & 86.44 & 100.00 & 90.80 & 6.78 & 0.00 & 4.60 & 6.78 & 0.00 & 4.60 \\
B & 91.14 & 83.33 & 89.13 & 5.88 & 0.00 & 4.35 & 2.94 & 16.67 & 6.52 \\
C & 97.87 & 81.81 & 94.83 & 0.00 & 9.09 & 1.72 & 2.13 & 9.09 & 3.45 \\
D & 89.29 & 100.00 & 91.67 & 7.14 & 0.00 & 5.56 & 3.57 & 0.00 & 2.78 \\
E & 93.10 & 100.00 & 95.12 & 0.00 & 0.00 & 0.00 & 6.90 & 0.00 & 4.88 \\
\hline
\end{tabular}

Note.Specificity coding involved classifying topic segments (with complexity coding of 3 points or higher) into one of the 3 types- single event memories, summary episodic memories and summary generic memories.

${ }^{a}$ Biopsychosocial interview

Table 2 depicts the narrative complexity ratings, separately for the biopsychosocial interviews and the initial therapy sessions. The results indicate that the percentage of narratives at the 3 point level ranged between $40 \%$ and $71 \%$ ) in the biopsychosocial interviews, and continued to be high in the therapy sessions (with a range of $27 \%$ to $76 \%$ ). There was an increase in the percentage of narratives at the 5 point level in the therapy sessions, for four clients. However, no clear pattern was present for the narrative descriptions at the other levels of complexity while comparing the biopsychosocial interview and therapy sessions.

The narrative units that were at 3 points or higher were examined to identify autobiographical memories (depicting events that were personally experienced and that took place at least 12 months ago). The percentage of narratives defined as autobiographical was high in both biopsychosocial interview and therapy sessions, with a range of $92 \%$ to

$100 \%$ during the interviews. A decrease in the percentage of autobiographical memories (75\%$85 \%$ ) was evident during the therapy sessions.

Specificity coding (combining the data from in- terviews and therapy sessions) indicated that all five clients largely produced narratives that were summary generic - a single recollection of memories that blended repeated occurrences of a similar event separated over larger periods of time (range of $89 \%$ to $95 \%$ ). There were a small percentage of summary episodic and single event memories (below 10\%) that emerged in both the interview as well as therapy sessions (Table 3 ).

Table 3 shows that the percentage of generic narratives remained high during the interview as well as therapy sessions (above 80\%) for all clients. However, there are individual differences in the changes from the interviews to the therapy sessions, for instance-Client $\mathrm{C}$ had a decrease in generic memories, with increase in episodic and specific memories, while there was an increase in generic memories and decrease in specific memories during the initial phase of therapy for Client $\mathrm{E}$.

The capacity to step back from memories and make meaning out of them, seemed to be impaired in the sample. Table 4 indicates that memories were predominantly poorly integrated (more than $80 \%$ ) for all clients, both during the biopsychosocial in- 


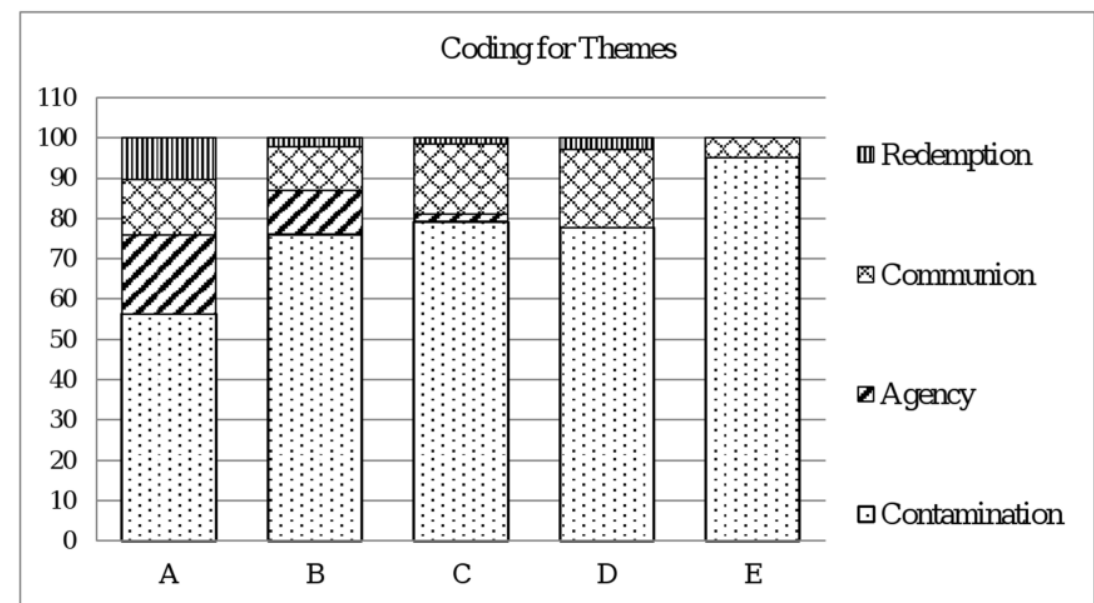

Figure 3. Percentage distribution of thematic coding of topic segments from both biopsychosocial interview sessions and first five therapy sessions $(n=5)$.

terviews and the initial phase of therapy. Therefore memories were largely recalled as factual occurrences, without having extracted meanings or implications for the understanding of the self. Despite the variations in the individual patterns of increase or decrease in the integration of memories as therapy progressed, there was a consistent trend suggesting persisting difficulties in meaning-making.
As indicated in Figure 3, themes of contamination were found to be the most predominant, in the interviews and therapy sessions combined (56\% to $95 \%$ ). Some of the contamination sequences indicated lack of attention from parental figures, physical abuse, parental discord, disappointment and dejection in childhood. Disappointment, discord and lack of support were also found to be continuing in

Table 4. Percentage distribution of topic segments coded for integration in the biopsychosocial interview sessions and first five therapy sessions $(n=5)$

\begin{tabular}{|ccccccc|}
\hline & \multicolumn{3}{c}{$\begin{array}{c}\text { Integrated } \\
\text { \% }\end{array}$} & \multicolumn{2}{c|}{} & \multicolumn{2}{c|}{$\begin{array}{c}\text { Non-integrated } \\
\text { Client }\end{array}$} & BPS $^{\mathrm{a}}$ & Therapy & Combined & BPS $^{\mathrm{a}}$ & Therapy & Combined \\
\cline { 2 - 7 } & 16.95 & 17.86 & 17.24 & 83.05 & 82.14 & 83.76 \\
A & 0.00 & 0.00 & 0.00 & 100.00 & 100.00 & 100.00 \\
C & 2.13 & 0.00 & 1.72 & 97.87 & 100.00 & 98.28 \\
D & 0.00 & 0.00 & 0.00 & 100.00 & 100.00 & 100.00 \\
E & 0.00 & 16.66 & 4.88 & 100.00 & 83.33 & 95.12 \\
\hline
\end{tabular}

Note. Integration coding involved classifying topic segments (with complexity coding of 3 points or higher) into integrated or nonintegrated memories.

${ }^{\text {a } B i o p s y c h o s o c i a l ~ i n t e r v i e w . ~}$

Table 5. Percentage distribution of topic segments coded for themes in biopsychosocial interview sessions and first five therapy sessions $(n=5)$

\begin{tabular}{|ccccccccc|}
\hline \multirow{2}{*}{ Client } & \multicolumn{2}{c}{$\begin{array}{c}\text { Contamination } \\
\text { \% }\end{array}$} & \multicolumn{2}{c}{$\begin{array}{c}\text { Agency } \\
\%\end{array}$} & \multicolumn{2}{c}{$\begin{array}{c}\text { Communion } \\
\%\end{array}$} & \multicolumn{2}{c|}{$\begin{array}{c}\text { Redemption } \\
\%\end{array}$} \\
\cline { 2 - 10 } & BPS $^{\mathrm{a}}$ & Therapy & BPS $^{\mathrm{a}}$ & Therapy & BPS $^{\mathrm{a}}$ & Therapy $^{\text {BPS }}$ & Therapy $^{\mathrm{a}}$ \\
\hline $\mathrm{A}$ & 57.63 & 53.57 & 13.56 & 32.14 & 18.64 & 3.57 & 10.17 & 10.17 \\
B & 73.53 & 83.33 & 8.82 & 16.67 & 14.71 & 0.00 & 2.94 & 0.00 \\
C & 80.85 & 72.72 & 2.13 & 0.00 & 17.02 & 18.18 & 0.00 & 9.09 \\
D & 71.43 & 100.00 & 3.57 & 0.00 & 0.00 & 0.00 & 25.00 & 0.00 \\
E & 96.55 & 91.67 & 0.00 & 0.00 & 3.45 & 8.33 & 0.00 & 0.00 \\
\hline
\end{tabular}

\footnotetext{
${ }^{\mathrm{a} B i o p s y c h o s o c i a l ~ i n t e r v i e w . ~}$
} 
current relationships. Themes of agency (themes of power, achievement, mastery, independence, autonomy, separation) and communion (themes of relationship, connection, intimacy, nurturance, helping, togetherness) were not found for two participants, while these were found to be in the range of $1 \%$ to $20 \%$ for the other three clients. Themes of redemption, reflecting negative events transforming into triumph, growth, rejuvenation, and positive emotion were relatively the least for all clients $(10 \%$ and below).

Table 5 shows that contamination sequences were high in the biopsychosocial interviews as well as therapy sessions. Redemption and agency themes were absent in the therapy sessions for three clients and for two clients in the interviews. The theme of communion was found to be below $20 \%$ in both the therapy sessions and interviews.

\section{Discussion}

Autobiographical memories of lived experiences form one of the building blocks of an individual's narrative identity (Singer, Blagov, Berry \& Oost, 2013), and their structure and content are assumed to reflect the quality of psychological health and wellbeing. The present study revealed that emergent autobiographical memory narratives of clients with borderline personality disorder were at a moderate complexity level, tended to be generic in nature, non-integrated and containing predominantly contamination themes.

The CS-AMNP applied to the transcripts in the biopsychosocial interview and therapy sessions, indicated that most of the clients' descriptions were at moderate complexity level, with some indication of causality, but without clear outcome and temporal sequencing ( 3 point level of complexity).

An illustrative excerpt from the transcripts of one of the client's narratives about trouble making friends includes general descriptions of emotions and representations of individuals and the time marker identified is vague.

C: Normally, I am a very chatty person... like I can...people normally.. like I can talk a lot with people... like I have been a student ambassador...like fit to be a student ambassador.. to go on tours..to go on campus..like give campus tours to new students.. But... I have never been.... accepted as a friend and I always feel it is my fault... and I always think I am not good enough to have a friend....

$\mathrm{T}$ : Could you give me any examples?

C: Ummmm.... well just recently.... recently I went to this aboriginal camp...just to look at aboriginal students and make them aware that.. how education is... ... so we were looking at these indigenous groups...um local students... so we went there and there were lots of girls..doing stuff...like the way I am...like studying nursing or something like that..and they're good kids.... but what happened was they would start calling me for these meetings and text me to come for meetings... but I would never go...at one point I would feel like they won't like me if I am there... at some point they would just stop contacting me completely... and I then I would say... look they are not contacting me any more. So that would sort of um.. basically how it would work... I never actually made the time for my friends... because I always had a fear that they would not like me if they knew me.

Interestingly, it was found that some of the potentially most difficult or painful emotional experiences in childhood, such as incidents of abuse or interpersonal violence, were narrated in passing, with a complete absence of a story built around that experience ( 1 point level of complexity). Clients often referred to these incidents in the form of brief phrases while narrating unrelated issues or experiences. For example, the following excerpt includes the description of the client's relationship with the domestic help. It suggests inappropriate sexual behaviour by the domestic help, with a lack of concrete details or associated emotions.

C: We also had a maid while growing up..her name was $\mathrm{M}^{* * * *}$.. I loved $\mathrm{M}^{* * * *}$.. she was like a mother to me...... She used to take care of us.. wash us.. cook for us... And I still love her.. you know.. she's part of the family..I still talk to her... I go hug her.. nuzzle into her.. I know what she smells like. So $\mathrm{M}^{* * * *}$ is like family...you know it's like even if she steals something from our house, I wouldn't complain...she's like a mother to me.... There was also a time when $\mathrm{M}^{* * * *}$ asked me and my brother to sleep on top of her.... but.. we didn't... and you know she used to do so much to take care of us.. and wash us.. and get us ready...

Therapists therefore may need to be especially alert during the unfolding of life stories, so as to avoid missing out on clues, which are quickly passed over by the clients. Often, stories categorized at a lower level of complexity ( 1 and 2 points), lacked affective content and clarity of outcome, providing the therapist much room to speculate on the impact of events. In addition, some segments at the lower levels were considerably fragmented, sometimes creating a feeling of being "lost in the chaos" of the client's life, for the therapist. These 'incomplete stories' could pose challenges to therapists trying to discern the essence of their clients' narratives.

Findings along similar lines indicated that the central life story memories of BPD patients were illformed, incoherent and atypical resulting in disorganized narratives (Jorgensen et al., 2012) and the stories themselves lacked a strong sense of narrative 
coherence (Adler et al., 2012). The difficulties in constructing coherent narratives among individuals with BPD have been linked with deficits in mentalization due to their early attachment vulnerabilities. The compromised mentalization is explained to be a defense against painful or traumatic experiences, safeguarding the individual from interpreting the action and intentions of the self and other (Bateman \& Fonagy, 2003). Dimaggio and Semerari (2001) clarify that the effect of a good narrative is the integration of bodily experience, the construction of meanings, and interpersonal relations. The lack of coherent narratives or poor quality of narratives may therefore create ambiguity in the therapist's understanding of the client's difficult experiences and subsequently lower clarity in potential areas of intervention. Therefore, using deficits in narrative complexity as targets for intervention may be worthwhile to consider in the process of psychotherapy.

It was found that the narratives were largely autobiographical memories in the interviews as expected, and continued to be so even in the therapy sessions, indicating the importance of the references to past life experiences and events in the lives of BPD clients. However, these memories tended to be generic in nature, with little descriptions of specific or episodic narratives. In terms of narrative specificity, clients mainly provided summary generic memories (that blend the repeated occurrences of a similar event separated over larger blocks of time into an amalgamated single recollection), which typically stretched over a large temporal area such as childhood or college years, or period of stay with a parental figure or partner. A few studies have confirmed the tendency for individuals with BPD to overgeneralize their memories contributing to a lack of specificity in their narratives (Maureux et al., 2010; Startup et al., 2001). The protective function of overgeneralised memories has been suggested in studies with college students which link lower specificity with repressive defensiveness (Blagov \& Singer, 2004) and lower levels of subjective stress in the face of negative events. Similarly, it was found that the emotional impact of a negative event (Raes, Hermans, DeDecker, Eelen \& Williams, 2003). A model of personal event retrieval postulated the mechanisms by which emotionally disturbed patients defensively avoid the emotional impact of autobiographical memories by summarising categories of events (Williams et al., 2007).

All clients were found to have largely nonintegrated memories and research has linked this with lower levels of socio-emotional maturity and personal adjustment (Blagov \& Singer, 2004). Adler and colleagues (2012) also found that the narrator of life stories in the BPD group rarely reflected on the personal significance of a given episode or related it to his or her broader sense of self. Some theo- retical hypotheses indicate that early maltreatment and insecure attachment may negatively impact the ability to reminisce about events with an older adult and extract meaning out of the same (Valentino, 2011), which could perhaps lead to problems in integration of narratives among individuals with borderline psychopathology.

One could also consider cultural aspects of narratives while commenting on the tendency to reflect on them or integrate them into conceptualizations about the self. Several studies have found that personal memories of North Americans tend to be more self-focused than those of East Asians (e.g., Wang, 2001, 2006 as cited in McAdams, 2011). In collectivist cultures, children may be encouraged to assume a listening role over a telling role thereby prioritizing other selves and social contexts in their narratives (McAdams, 2011).

The thematic sequences in the narratives were largely those of contamination, indicating early experiences of neglect, abuse, lack of support resulting in emotional turmoil, fear of rejection and intense negative affect. For instance when a client saw improvements in her troubled marital relationship, she was sent away from home by her husband; when a client's graduate study plans were approved by the family, they withdrew support during the application process; a client's trusted caretaker used interpersonal violence to control her behaviour; and the support of a sister who was once distant and uninvolved with the client drops almost immediately post marriage, leaving the client unsupported and lonely again. The contamination sequences reflected those experiences where clients began to see hope or positivity in terms of support, empathy or understanding from family members but ended in frustration, disappointment, and dejection. Jorgensen and colleagues (2012) found that individuals with BPD reported more negative memories compared to a group of individuals with OCD and a non-clinical sample.

Themes of agency, communion and redemption were few in the narratives of all the clients. A few examples illustrative of the theme of agency (power, achievement, mastery, independence, autonomy, separation) include a client's experience of completing college applications by herself despite the lack of support from her family; taking up a second job to meet living expenses; applying skills taught by the counsellor to deal with emotional difficulties. Themes of communion (themes of relationship, connection, intimacy, nurturance, helping, togetherness) were also found to be low among the clients. However, as seen in the example given below, some clients realised that despite troubled interpersonal relations, there were possibilities of change and those relationships, though imperfect, would endure. Here the client is describing the support and acceptance she receives from her fiancé (despi- 
te their initial break-up and struggles in their relationship, leading to their recent engagement), and his efforts to ensure their future together.

C: ....Around me people are... like my fiancé, like he's so supportive of me. So supportive... he is making plans. He is working so hard... he will say that ok I will do that and I will graduate quicker than I plan and then I will have a house... He is in Australia as well.... same university but he is doing accounting and I am doing science... so with my problems he never blames me.... or he never asks me why can't you be stronger....

Themes of redemption (negative events that begin with themes of struggles, obstacles, and setbacks, but end with moments of triumph, growth, rejuvenation, and positive emotion) were found in low percentages for all clients. A few narratives illustrated this theme, for instance-a client's long standing relationship with her counsellor, his role in bringing about significant avenues of change during her periods of distress and the continuity of his being a stable and important part of her life; and improvements in communication in a client's previously uninvolved family following family intervention. Adler and colleagues (2012) found themes of agency and fulfilment of needs to relate with others (communion fulfilment) to be lower among interview narratives of BPD individuals when compared to matched controls. They suggested that identity disturbance in individuals with BPD features can be conceptualized as problems in constructing a coherent narrative that portrays an agentic protagonist who is able to fulfil his or her communal needs.

The study indicated that autobiographical memory narratives of individuals with BPD do not possess the characteristics of a healthy narrative identity (Singer et al., 2013) including memory specificity, a greater emphasis on positive affective content, and the capacity to engage in meaningmaking based on memory narratives. However these aspects are important for psychological health and well-being (Singer \& Conway, 2011). The logical question therefore would be what processes or techniques in psychotherapy could facilitate a healthy autobiographical memory system and a narrative identity that can contribute to positive mental health among these clients. Therapy could facilitate this process by helping clients express frightening childhood experiences in words and build a story that makes these experiences understandable and manageable. It may also help "re-story" negative experiences in a new light to alter social relationships and interpersonal functioning. Clients may also benefit from questioning stories told by others about them and consider their own perspectives and draw meaning instead.

Few studies have examined the association between narrative coherence and psychotherapy, where therapy led to positive results including an increase in narrative coherence (Fonagy et al., 1996; Levy et al., 2006). Serrano and colleagues (2004) investigated specific interventions to improve specificity of autobiographical memories among depressed older adults and suggest that autobiographical retrieval practice has positive benefits to relieve depression. Techniques like soothing, stressing emotional validation and identification of emotional nuclei were found to help in the transformation of self narratives (Salvatore et al., 2006). However, specific techniques to facilitate themes like redemption, agency and communion have not been investigated in the literature. Nonetheless, therapists could possibly include tasks within or outside therapy sessions, that may help clients experience positive emotions and develop a sense of agency. Therefore future research exploring suitable techniques and strategies to facilitate transformation of problematic narratives may prove worthwhile in the area of narrative-informed psychotherapy.

This study has a wide range of implications for clinical practice. The narrative conceptualization of pathology provides a metaphor for understanding the clients from multiple theoretical orientations (Adler, Chin, Kolisetty, \& Oltmanns, 2012). The understanding of narrative patterns in the early phase can strengthen case conceptualization and aid the extraction of critical narrative themes that may be submerged in the mass of autobiographical material generated in therapy sessions (Singer \& Bonalume, 2010b). An exercise in analysing narratives as part of therapy training can sensitize therapists to the kind of themes and affective scripts that individuals with BPD may be presenting. Incomplete stories and stories with low complexity might be missed by the therapist but 'heard' again while going through therapy transcripts. Clients with developmental vulnerabilities and difficult trajectories might benefit from enough time to express their 'life stories' in the initial phase of therapy and methodologies like the life story interviews and other similar approaches could be integrated into training programmes.

The study has limitations in terms of the small sample size and the absence of standardised diagnostic tools for sample selection. Potential patterns of change in narrative complexity, specificity, integration and themes of autobiographical memories, from the biopsychosocial interviews to the therapy sessions, could not be adequately examined due to the small sample. There is scarce research evidence or information about the psychometric properties of the biopsychosocial interview. The step of coding for themes in the coding system CSAMNP has not been tested extensively for its reliability and validity. Moertl, Boritz, Bryntwick and Angus (2010) critiqued the biopsychosocial inter- 
view for a skew towards negative or problematic stories in the initial encounter with clients. They also opined that the CS-AMP coding system, with the one year cut-off point for defining autobiographical memories, would exclude more recent critical events that led to client help-seeking. In a rejoinder, Singer \& Bonalume (2010b) highlighted the holistic approach of the interview process encompassing both resilience and challenges and also emphasised their focus on long-term memories that have become embedded into the sense of self and linked with other memories and affective scripts (Conway, Singer, \& Tagini, 2004). There are ongoing debates related to unpacking the concept of narrative coherence and possible overlaps with narrative complexity as defined in the present study (Adler, 2010). The theoretical conceptualisation and measurement of coherence needs further clarification in future research on psychotherapy narratives.

An important and inadequately addressed question pertains to possible systematic differences in the characteristics of autobiographical memoires emerging in the structured interviews focused on memory recollection and those identified in the initial therapy sessions. The results pertaining to these two phases have been segregated to facilitate comparisons with future therapeutic studies which may not include the biopsychosocial interview.

Studies of narrative processes in psychotherapy have used varied research designs ranging from intensive single case designs (Angus \& Kagan, 2013; Gullestad \& Wilberg, 2011), a single group design with few cases of a specific disorder like depression (Levitt, Korman, \& Angus, 2000), two-group designs with either different therapy modalities (Boritz, Angus, Monette, Hollis-Walker, \& Warwar, 2011) or a clinical group and matched control group (Ramussen \& Angus, 1996). Studies with control groups have primarily used single psychotherapy sessions (Ramussen \& Angus, 1996) or a single autobiographical memory test (Reid \& Startup, 2010) and this may reflect the resource-intensive nature of qualitative research examining narrative material. Although the lack of a control group in the present study makes it possible that the findings are a reflection of general trends of psychopathology, and not specific to clients with BPD, the results may yet inform clinical practice and stimulate further research with this vulnerable group. It is critical that these preliminary findings be extended in future studies with a methodologically improved research design; a larger sample and inclusion of a matched control group. This would help to answer additional questions about the uniqueness of narrative structures and content among individuals with borderline pathology.

This study points to future research avenues examining memory narratives in psychotherapy. The research design employed in the study could be used as a template to conduct studies over a longer duration of therapy, documenting the process of change in memory narratives. The sequential changes in the therapy process could then be examined through the use of techniques such as sequential $\log$ linear analysis. The relationships between narrative content and structure and the theoretically linked constructs like affect regulation, mentalisation and attachment styles could be concurrently assessed. This could help answer relevant questions, for instance-Do changes in memory specificity influence changes in affect regulation or vice versa?; Does integration of narratives facilitate better interpersonal functioning?; Can working alliance be enhanced by eliciting autobiographical narratives in the early phase of therapy? and so on. $\mathrm{Ri}$ gorous research on the analysis of narrative patterns could also help in the construction of standardized tools to assess factors such as memory specificity, integration and themes. Further studies would also help in the validation of this coding system and its potential for further understanding borderline psychopathology as well as the process of psychotherapeutic change.

\section{Acknowledgements}

J. A. Singer and L. Bonalume for permission to use the Biopsychosocial interview and The Coding System of Autobiographical Memory Narratives, as well as for their constructive suggestions.

\section{References}

Adler, J.M. (2010). Commentary on autobiographical memory narratives in psychotherapy: a coding system applied to the case of Cynthia: Rising to the challenges of identifying and analyzing clients' narratives. Pragmatic Case Studies in Psychotherapy, 6, 189-202. doi: 10.14713/pcsp.v6i3.1042

Adler, J.M. (2012). Living into the story: Agency and coherence in a longitudinal study of narrative identity development and mental health over the course of psychotherapy. Journal of Personality and Social Psychology, 102(2), 367-389. doi: 10.1037/a0025289

Adler, J.M., Chin, E.D., Kolisetty, A.P., \& Oltmanns, T.F. (2012). The distinguishing characteristics of narrative identity in adults with features of borderline personality disorder: An empirical investigation. Journal of Personality Disorders, 26(4), 498-512. doi: 10.1521/pedi.2012.26.4.498

Arntz, A., Meeren, M., \& Wessel, I. (2002). No evidence for overgeneral memories in borderline personality disorder. Behaviour Research and Therapy, 40(9), 1063-1068. doi: 10.1016/s0005-7967(01)00121-8

American Psychiatric Association. (2000). Diagnostic and Statistical Manual of Mental Disorders (4th ed., text revision). Washington, DC: Author.

Angus, L., \& Kagan, F. (2013). Assessing client self-narrative change in emotion-focused therapy of depression: An intensive single case analysis. Psychotherapy, 50(4), 525-534. doi: $10.1037 / \mathrm{a} 0033358$

Angus, L.E., \& Greenberg, L.S. (2011). Working with narrative in emotion-focused therapy: Changing stories, healing lives. Washington, DC: American Psychological Association. doi: $10.1037 / 12325-000$ 
Angus, L., Levitt, H., \& Hardtke, K. (1999). The narrative processes coding system: Research applications and implications for psychotherapy practice. Journal of Clinical Psychology, 55(10), 1255-1270. doi: 10.1002/(sici)1097-4679 (199910)55:10<1255::aid-jclp7>3.0.co;2-f

Angus, L., Lewin, J., Boritz, T., Bryntwick, E., Carpenter, N., Watson-gaze, J., \& Greenberg, L. (2012). Narrative processes coding system: A dialectical constructivist approach to assessing client change processes in emotion-focused therapy of depression. Research in Psychotherapy: Psychopathology, Process and Outcome, 15(2), 54-61. doi: 10.7411/ RP.2012.006

Avdi, E., \& Georgaca, E. (2007). Narrative research in psychotherapy: A critical review. Psychology and Psychotherapy, 80, 407-419. doi: 10.1348/147608306x158092

Bateman, A., \& Fonagy, P. (2003). The development of an attachment based treatment program for borderline personality disorder. Bulletin of the Menninger Clinic, 67, 187211. doi: 10.1521/bumc.67.3.187.23439

Bauer, J.J., McAdams, D.P., \& Pals, J.L. (2008). Narrative identity and eudaimonic well-being. Journal of Happiness Studies, 9, 81-104. DOI:10.1007/s10902-006-9021-6

Blagov, P.S., \& Singer, J. (2004). Four dimensions of selfdefining memories (specificity, meaning, content, and affect) and their relationships to self-restraint, distress, and repressive defensiveness. Journal of Personality, 72(3), 481511. doi: 10.1111/j.0022-3506.2004.00270.x

Boritz, T.Z., Angus, L., Monette, G., \& Hollis-Walker, L. (2008). An empirical analysis of autobiographical memory specificity subtypes in brief emotion-focused and clientcentered treatments of depression. Psychotherapy Research, 18(5), 584-593. doi: 10.1080/10503300802123245

Boritz, T.Z., Angus, L., Monette, G., Hollis-Walker, L., \& Warwar, S. (2011). Narrative and emotion integration in psychotherapy: Investigating the relationship between autobiographical memory specificity and expressed emotional arousal in brief emotion-focused and client-centred treatments of depression. Psychotherapy Research, 21(1), 16-26. doi: 10.1080/10503307.2010.504240

Chance, S.E; Bakeman, R, Kaslow, N.J, Farber, E, \& BurgeCallaway, $\mathrm{K}$ (2000). Core conflictual relationship themes in patients diagnosed with borderline personality disorder who attempted, or who did not attempt suicide. Psychotherapy Research, 10(3), 337-355. doi: 10.1093/ptr/ 10.3.337

Conway, M.A., \& Pleydell-Pearce, C.W. (2000). The construction of autobiographical memories in the selfmemory system. Psychological Review, 107, 261-288. doi: 10.1037/0033-295x.107.2.261

Conway, M.A., Singer, J.A., \& Tagini, A. (2004). The self and autobiographical memory: correspondence and coherence. Social Cogniton, 22(5), 491-529. doi: 10.1521/soco.22.5. 491.50768

Dimaggio, G., \& Semerari, A. (2001). Psychopathological narrative forms. Journal of Constructivist Psychology, 14, 123. doi: 10.1080/10720530125913

Fonagy, P., Leigh, T., Steele, M., Steele, H., Kennedy, R., Mattoon, G., Target, M., \& Gerber, A. (1996). The relation of attachment status, psychiatric classification and response to psychotherapy. Journal of Consulting and Clinical Psychology, 64, 22-31. doi: 10.1037/0022-006x.64.1.22

Fonagy, P. (2000). Attachment and borderline personality disorder. Journal of the American Pychoanalytic Association, 48(4), 1129-1146. doi: 10.1177/00030651000480040701

Fuchs, T. (2007). Fragmented selves: Temporality and identity in borderline personality disorder. Psychopathology, 40(6), 379-387. doi: 10.1159/000106468

Greenberg, L.S., Rice, L.N., \& Elliott, R. (1993). Facilitating emotional change: The moment-by-moment process. New
York: Guilford Press.

Gullestad, F.S., \& Wilberg, T. (2011). Change in reflective functioning during psychotherapy. A single-case study. Psychotherapy Research, 21(1), 97-111. doi: 10.1080/ 10503307.2010.525759

Helgeland, M.I., \& Torgersen, S. (2004). Developmental antecedents of borderline personality disorder. Comprehensive Psychiatry, 45(2), 138-147. doi: 10.1016/j.comppsych. 2003.09.001

Jones, B.B., Heard, H.H., Startup, M.M., Swales, M.M., Williams, J.G., \& Jones, R.P. (1999). Autobiographical memory and dissociation in borderline personality disorder. Psychological Medicine, 29(6), 1397-1404. doi: 10.1017/ s0033291799001208

Jorgensen, C.R., Berntsen, D., Bech, M., Kjølbye, M., Bennedsen, B.E., \& Ramsgaard, S.B. (2012). Identityrelated autobiographical memories and cultural life scripts in patients with Borderline Personality Disorder. Consciousness and Cognition, 21(2), 788-798. doi: 10.1016/ j.concog.2012.01.010

Kremers, I.P., Spinhoven, P., \& Van der Does, A.J.W. (2004). Autobiographical memory in depressed and non-depressed patients with borderline personality disorder. British Journal of Clinical Psychology, 43, 17-29. doi: 10.1348/ 014466504772812940

Levitt, H., Korman, Y., \& Angus, L. (2000). A metaphor analysis in treatments of depression: Metaphor as a marker of change. Counselling Psychology Quarterly, 13(1), 23-35. doi: 10.1080/09515070050011042

Levy, K.N., Meehan, K.B., Kelly, K.M., Reynoso, J.S., Weber, M., Clarkin, J.F., \& Kernberg, O.F. (2006). Change in attachment patterns and reflective function in a randomized control trial of transference-focused psychotherapy for borderline personality disorder. Journal of Consulting and Clinical Psychology, 74(6), 1027-1040. doi: 10.1037/0022006x.74.6.1027

Linehan, M.M. (1993a). Cognitive Behavioral Treatment of Borderline Personality Disorder. New York: Guilford Press.

Linehan, M.M. (1993b). Skills training manual for treating Borderline Personality Disorder. New York: Guilford Press.

Luborsky, L. (1977). Measuring a pervasive psychic structure in psychotherapy: The Core Conflictual Relationship Theme. In N. Freedman \& S. Grand (Eds.), Communicative structures and psychic structures (pp. 367-395). New York: Plenum Press.

Matos, M., Santos, A., Gonçalves, M., \& Martins, C. (2009). Innovative moments and change in narrative therapy. Psychotherapy Research, 19(1), 68-80. doi: 10.1080/ 10503300802430657

Maurex, L., Lekander, M., Nilsonne, A., Andersson, E., Asberg, M., \& Ohman, A. (2010). Social problem solving, autobiographical memory, trauma, and depression in women with borderline personality disorder and a history of suicide attempts. British Journal of Clinical Psychology, 49(3), 327-342. DOI: $10.1348 / 014466509 \times 454831$

McAdams, D.P. (2011). Narrative identity. In S.J. Schwartz, K. Luyckx \& V.L. Vignoles (Eds.), Handbook of identity theory and research (pp. 99-115). New York, NY: Springer New York.

McAdams, D.P., \& Pals, J.L. (2006). A new Big Five: Fundamental principles for an integrative science of personality. American Psychologist, 61(3), 204-217. doi: 10.1037/ 0003066x.61.3.204

McLean, K.C. (2008). The emergence of narrative identity. Social and Personality Psychology Compass, 2, 1685-1702. doi: 10.1111/j.1751-9004.2008.00124.x

Mendes, I., Ribeiro, A.P., Angus, L., Greenberg, L.S., Sousa, I., \& Goncalves, M.M. (2010). Narrative change in emotionfocused therapy: how is change constructed through the 
lens of the innovative moments coding system? Psychotherapy Research, 20(6), 692-701. doi: 10.1080/10503307 .2010 .514960

Moertl, K., Boritz, T.Z., Bryntwick, E., \& Angus, L. (2010). Developing a systematic procedure for the assessment of self-defining memories in psychodynamic therapy: Promise and pitfalls. Pragmatic Case Studies in Psychotherapy, 6(3), 203-214. doi: 10.14713/pcsp.v6i3.1043

Pinsker, H. (1997). A primer of supportive psychotherapy. New Jersey: Analytic Press.

Raes, F., Hermans, D., DeDecker, A., Eelen, P., \& Williams, J.M.G. (2003). Autobiographical memory specificity and affect regulation: An experimental approach. Emotion, 3(2), 201-206. doi: 10.1037/1528-3542.3.2.201

Rasmussen, B., \& Angus, L. (1996). Metaphor in psychodynamic psychotherapy with borderline and non-borderline clients: A qualitative analysis. Psychotherapy, 33(4), 521530. doi: 10.1037/0033-3204.33.4.521

Reid, T., \& Startup, M. (2010). Autobiographical memory specificity in borderline personality disorder: associations with co-morbid depression and intellectual ability. The British Journal of Clinical Psychology, 49, 413-420. doi: 10.1348/014466510x487059

Renneberg, B., Theobald, E., Nobs, M., \& Weisbrod, M. (2005). Autobiographical memory in borderline personality disorder and depression. Cognitive Therapy and Research, 29(3), 342-358. doi: 10.1007/s10608-005-4267-4

Salvatore, G., Conti, L., Fiore, D., Carcione, A., Dimaggio, G., $\&$ Semerari, A. (2006). Disorganized narratives: Problems in treatment and therapist intervention hierarchy. Journal of Constructivist Psychology, 19(2), 191-207. doi: 10.1080/ 10720530500508936

Serrano, J.P., Latorre, J.M., Gatz, M., \& Montanes, J. (2004). Life review therapy using autobiographical retrieval practice for older adults with depressive symptomatology. Psychological Aging, 19(2), 270-277. doi: 10.1037/0882-7974. 19.2.272

Singer, J.A., \& Blagov, P.S. (2002). Classification system and scoring manual for self-defining autobiographical memories. Department of Psychology, Connecticut College, New London, CT.
Singer, J.A., Blagov, P., Berry, M., \& Oost, K.M. (2013). Selfdefining memories, scripts, and the life story: narrative identity in personality and psychotherapy. Journal of Personality, 81(6), 569-582. doi: 10.1111/jopy.12005

Singer, J., \& Bonalume, L. (2010a). Autobiographical memory narratives in psychotherapy: A coding system applied to the case of Cynthia. Pragmatic Case Studies in Psychotherapy, 6, 134-188. doi: 10.14713/pcsp.v6i3.1041

Singer, J.A., \& Bonalume, L. (2010b). Toward the scientific study of autobiographical memory narratives in psychotherapy. Pragmatic Case Studies in Psychotherapy, 6(3), 215-222. doi: 10.14713/pcsp.v6i3.1044

Singer, J.A., \& Conway, M.A. (2011). Reconsidering therapeutic action: Loewald, cognitive neuroscience and the integration of memory's duality. The International Journal of Psychoanalysis, 92(5), 1183-1207. doi: 10.1111/ j.1745-8315.2011.00415.x

Shadish, W.R., Matt, G.E., Navarro, A.M., \& Phillips, G. (2000). The effects of psychological therapies under clinically representative conditions: A meta-analysis. Psychological Bulletin, 126(4), 512-529. doi: 10.1037/0033-2909. 126.4.512

Startup, M., Heard, H., Swales, M., Jones, B., Williams, J.M., \& Jones, R.S. (2001). Autobiographical memory and parasuicide in borderline personality disorder. The British Journal of Clinical Psychology, 40, 113-120. doi: 10.1348/ 014466501163535

Valentino, K. (2011). A developmental psychopathology model of over-general autobiographical memory. Developmental Review, 31(1), 32-54. doi: 10.1016/j.dr.2011.05. 001

Williams, J.M.G., Barnhofer, T., Crane, C., Herman, D., Raes, F., Watkins, E., \& Dalgleish, T. (2007). Autobiographical memory specificity and emotional disorder. Psychological Bulletin, 133(1), 122-148. doi: 10.1037/0033-2909.133.1. 122

World Health Organisation. (1992). ICD-10 classification of mental and behavioural disorders: clinical descriptions and diagnostic guidelines. Geneva: World Health Organisation.

Submitted June 14, 2014

Revision accepted October 14, 2014

Published March 1, 2015 